\title{
The Godparent Plan
}

\section{A Pedagogical Strategy for CS1 Accompaniment and CS2 Pedagogical Enhancement}

\author{
https://doi.org/10.3991/ijep.v8i1.7596 \\ Pedro Guillermo Feijóo García $\left.{ }^{\bowtie}\right)$, Carlos Hernán Ortíz Buitrago \\ Universidad El Bosque, Bogotá D.C., Colombia \\ pfeijoo@unbosque.edu.co
}

\begin{abstract}
Courses such as CS1 and CS2 can present an interesting pedagogical challenge when it comes to the theory-practice relationship, along with aspects that involve the course's logistics, the programming language used, and the characteristics of the students involved in the process. This study presents an innovative didactic approach, oriented towards the accompaniment of CS1 students by CS2 students at Universidad El Bosque, Colombia, seeking with this Godparent Plan, to provide a personalized accompaniment to first semester students, whereby CS2 students enhance their domain over concepts and skills while accompanying, explaining and teaching younger peers. The results of this study are favorable, outlining a didactic scheme that can be adapted and replicated in other curricular scenarios.
\end{abstract}

Keywords - active learning, validated learning, pedagogical innovation, computer science education, CS1 didactics, CS2 didactics

\section{Introduction}

Teaching in introductory courses, such as CS1 and CS2, poses an interesting pedagogical challenge as far as the theory-practice relationship is concerned. The instructor in charge must ease the immersion into the programming world for students coursing the first academic year, articulating high-quality standards in conjunction with motivation and didactic strategies to keep them motivated, confident and projected to continue in the program.

To enhance the pedagogical approach in these courses, within a curricular and logistic context that does not favor the articulation of constructivist approaches for active learning, a CS2 section was adapted, so that its students could work individually as godparents or tutors, with students from a CS1 section, both sections taught by the same instructor.

Although a general approach would invite to question the role of this Godparent Plan with respect to the CS1 course, throughout this document we will present the role of this proposal as a didactic strategy for meaningful learning in CS2, with the purpose to answer the following research question: How effective is peer tutoring for 
the tutor's academic enhancement, in terms of concepts and skills corresponding to programming?

This document is organized as follows: Section 2 presents some previous works, concepts of interest, and existing tools like the designed Application. Section 3 presents the problem addressed in this study, the purpose for undertaking this project and the obtained solution. The final part of this paper presents the study's conclusions and a proposal for future research related to this project.

\section{$2 \quad$ Related Studies}

There have been a variety of studies and approaches about peer tutoring as an effective didactical strategy for pedagogical enhancement. As a first example, Cottam et al. conducted a study with a tutoring program developed for CS1 and CS2 courses, looking to validate if this program helped students to build a sense of community and confidence to take further courses in the career, while succeeding in coursework [1]. For the tutoring program they proposed, they hired for each supervised class a graduate student supervisor and three undergraduate students, whose grade was $\mathrm{A}+$. Through the study, course performance improvements were observed, letting the authors identify that peer tutoring is an effective tool for academic retention in the program. Furthermore, the authors concluded that the program helped students to succeed in coursework, recommending this approach to be implemented not just in other courses at their institution, but also in other schools and curricula.

On a similar approach, Loos et al. present the design and implementation of a tutoring program at Indiana University, dividing the experiences according to three perspectives: instructor's perspective, the point of view of a peer tutor, and the perspective of a tutee who was taking the course [2]. First, the peer tutor was interviewed, and stated that the tutoring program helped towards strengthening the relationship with other peer tutors at the same semester, the program being helpful to solidify understanding towards concepts and topics she had to explain to her tutees. On the other hand, the interviewed tutee, indicated that the tutoring program helped her understand and learn the course concepts, motivating her to work hard to become a tutor in a near future. Finally, the instructor, indicated to have noticed an increase in the collaborative atmosphere of the course, the tutoring program effective towards improving understanding of course topics.

Considering other perspective, Weikle describes a different model for peer tutoring, proposed specially for small institutions. In this model, the payment scheme is replaced by academic credits, supplying the accompaniment with the Academic Support Center (ASC) staff. Working with nine tutors across a range of seven classes, the author concludes that the use of peer tutoring is tremendously successful, because it helps the student gain confidence towards programming concepts and skills. Furthermore, he concludes that this model helps provide feedback to students, enhancing concept understanding and skills acquisition [3].

A different study, conducted by Hug et al., describes the benefits of peer tutoring, stating that most peer leaders (tutors) reported increased self-efficacy in teaching 
computer science, while having improved understanding of the contents covered, and better communication and leader skills after one semester as tutors [4].

This study was conducted with 89 peer leaders, over five college semesters through six participant institutions, and is significantly important, because it focuses on the tutors' academic improvement.

\section{Pedagogical Foundation}

Before going further into the proposed Godparent Plan and the results of this pilot study, it is important to describe the pedagogical model to which it responds, and the taxonomy with which this didactic strategy is justified.

As Feijóo García et al. indicate, Constructivism focuses on understanding the learning subject, by identifying and reading his/her context and reality [5], trying to understand how it is possible to construct knowledge and learning within the context and reality identified, with new experiences and pedagogical approaches that allow the learning subject to evolve in his/her knowledge and abilities. Constructivism, as a pedagogical theory and model, strongly favors active learning, proposing the learning subject as the main actor of the whole pedagogical process, thus ensuring that the learning process is directed not towards teaching or transmitting concepts, but towards learning through educative approaches and enriching experiences [6].

In addition, and through its taxonomy, Fink focuses on the design of courses for meaningful learning, addressing six dimensions that he considers fundamental in the pedagogical process [7]:

1. Foundational Knowledge Dimension: Focused on understanding and remembering information and ideas.

2. Application Dimension: Centered on skills, critical thinking and managing projects.

3. Integration Dimension: Interested on the connection between ideas, people and realms of life.

4. Human Dimension: Focused on making the learning subject aware of himself/herself and others.

5. Caring Dimension: Centered on the development of new feelings, interests and values.

6. "Learning How to Learn" Dimension: Proposed to make the learning subject able to become a better learner, gaining the skills according to self-learning and critical learning awareness.

The articulation of these dimensions, along with contexts' reading and the identification of situational factors, means that the courses that incorporate this taxonomy manage to ensure that students have significant learning, considering that the taxonomy upholds the constructivist model, promoting through its dimensions a direct approach to active learning.

The Godparent Plan works globally with every one of the dimensions described, offering the godparent an effective didactic scenario for learning: teaching. This, 
bringing to light, the experience of Frager and Stern [8], which exposes the visible advantages of tutoring as a mechanism for meaningful learning, through results corresponding to the conjunction between fifth and sixth-grade children with first-grade children, focused on strengthening reading and writing skills.

Also, considering the results presented by Cortese [9], it is plausible to indicate that a tutoring approach strengthens tutors' social skills, given that, whilst teaching, they are faced with diversity scenarios, giving them the opportunity to recognize their own shortcomings and, therefore, learn to learn through interaction with others, considering the dimensions here described.

\section{$4 \quad$ Pedagogical Design}

For the execution of this pilot, two sections corresponding to a CS1 course and a CS2 course were articulated. Both courses were given by the same instructor, at Universidad El Bosque, Colombia.

The CS1 course of this study is an introductory course (first semester) to objectoriented programming, in which JAVA is used as the main programming language. In this course, the student learns to design and develop standalone applications, getting to the point of mastering the persistence of plain text files and managing matrices as 2D data structures.

On the other hand, the CS2 course (second semester), is a course that extends the knowledge acquired in CS1, complementing it with inheritance, polymorphism and interfaces management, in conjunction with General Responsibility Assignment Software Patterns (GRASP) [10] and program validation techniques (JUnit) [11].

The pilot had a total of 30 godparents, working together with 30 godchildren, to guarantee a personalized accompaniment to each CS1 student, limiting academic overload scenarios for any of the CS2 students, while providing assertive follow-up towards the godparents' process as tutors.

Several of the CS1 activities, conducted within this plan, were rated by CS2 students in a meeting modality, being most of them programming and algorithmic activities. For this purpose, the instructor provided a variety of rubrics to carry out peer evaluation. The tutor's main task, while monitoring or evaluating his godchild's activities, was to clarify doubts and explain how the task should be done.

Both godchildren and godparents were required to report weekly the quality of the meetings undertaken, describing what had been done and how was the counterpart's attitude.

To make this didactic strategy something interesting for the godparents, and seeking that they did not feel obliged to carry it out, the activity proposed a bonified evaluation scheme, taking into consideration for the bonus, the godchildren's academic performance by the end of CS1 activities, and the follow-up reports prepared and submitted by both actors.

The pilot study was conducted in four academic weeks, inviting godparents and godchildren to follow up for more than two hours and less than five hours a week. The godparents and godchildren selection was done by the instructor, considering 
academic aspects (grades and performance) as well as individual aspects (leadership skills, communication skills, personality).

\section{$5 \quad$ Results}

At the end of this pilot Godparent Plan, surveys were conducted with the participant godparents and godchildren, to understand how did they feel with this didactic strategy. In total, 27 godchildren and 28 godparents provided their feedback.

The participant godparents were generally between 18 and 20 years old $(60.7 \%)$, being the great majority male $(85.7 \%)$. On the other hand, the participant godchildren were generally less than 18 years old $(51.9 \%)$, and similarly to the godparents' distribution, they were mostly male $(85.2 \%)$.

As can be seen in Figure 1, 60.7\% of the godparents considered the Godparent Plan an excellent pedagogical strategy, followed by $35.7 \%$ who considered it a good strategy, and $3.6 \%$ who stated it was a bad strategy.

Similarly, as presented in Figure 2, 51.9\% of the participant godchildren considered the Plan an excellent pedagogical strategy, followed by $4.4 \%$ who considered it a good strategy, and $3.7 \%$ who stated it was a regular strategy.

On the other hand, being asked how much did they learn as godchildren, the majority of CS1 participant students indicated they learned very much $(59.3 \%)$, being just $3.7 \%$ who stated they learned nothing, and $37 \%$ indicated they learned a little (see Figure 3).

However, as can be seen in Figure 4, the godparents presented a different behavior towards this same question. In their case, $78.6 \%$ of the CS2 participating students, stated they learned very much through this didactic strategy, followed by $14.3 \%$ who indicated they learned a little, and $7.1 \%$ who said they learned nothing through the process.

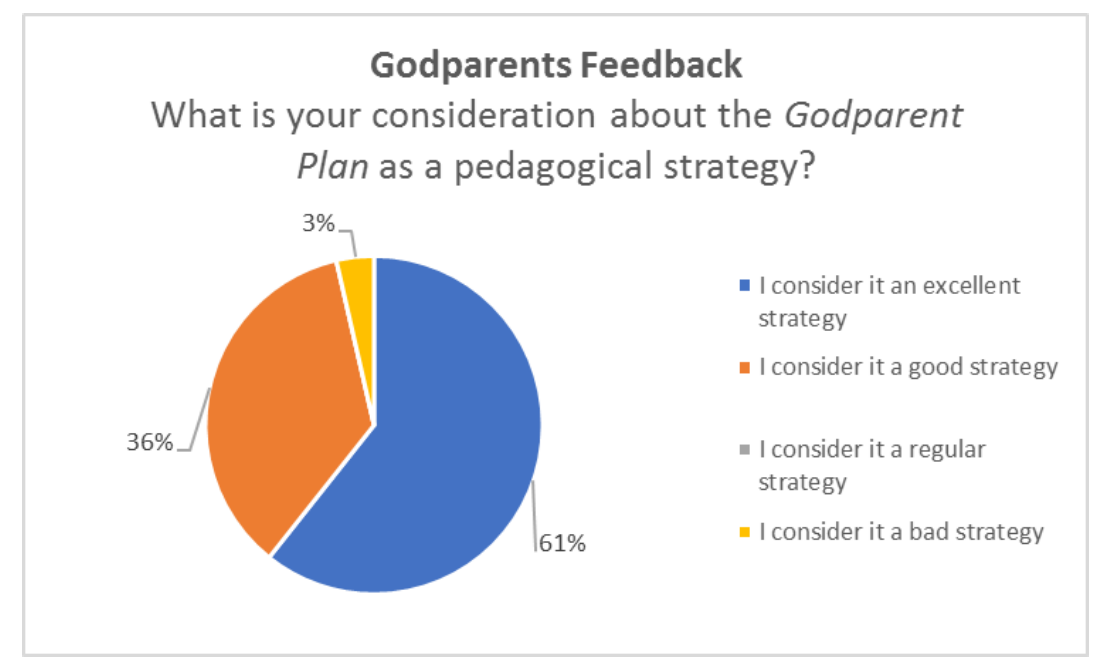

Fig. 1. Godparents' consideration about the Godparent Plan as a pedagogical strategy 


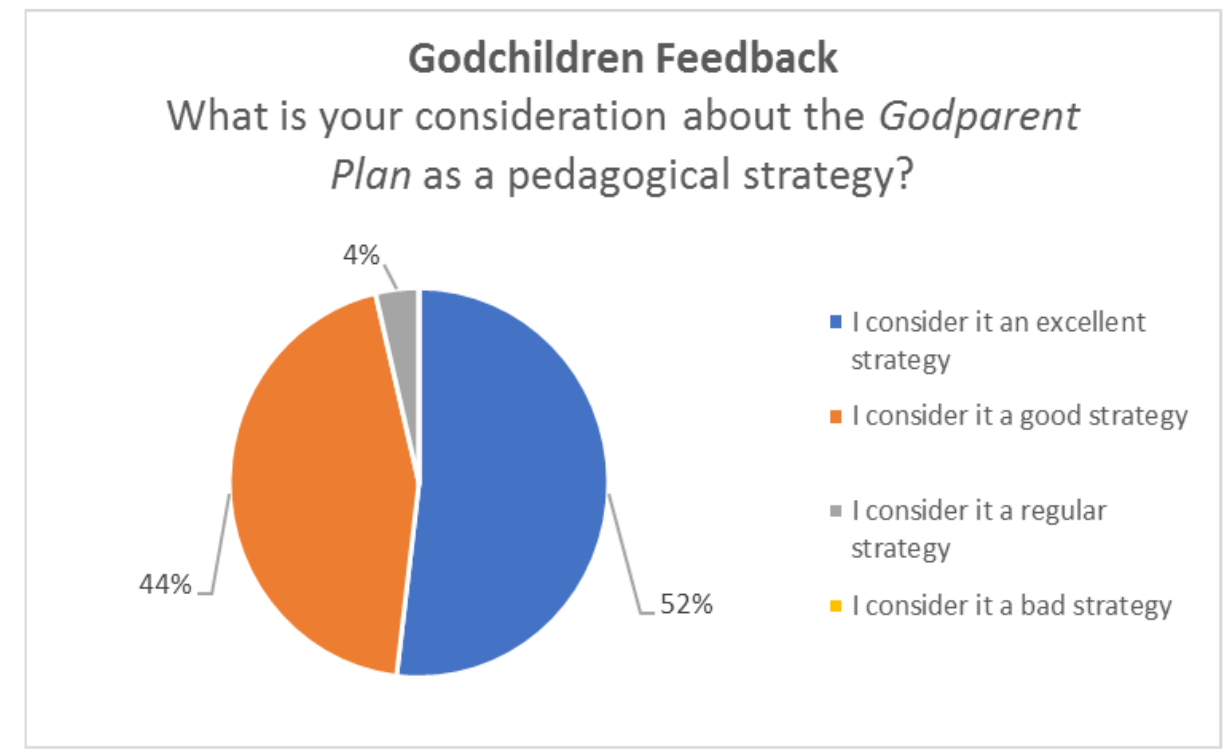

Fig. 2. Godchildren' consideration about the Godparent Plan as a pedagogical strategy
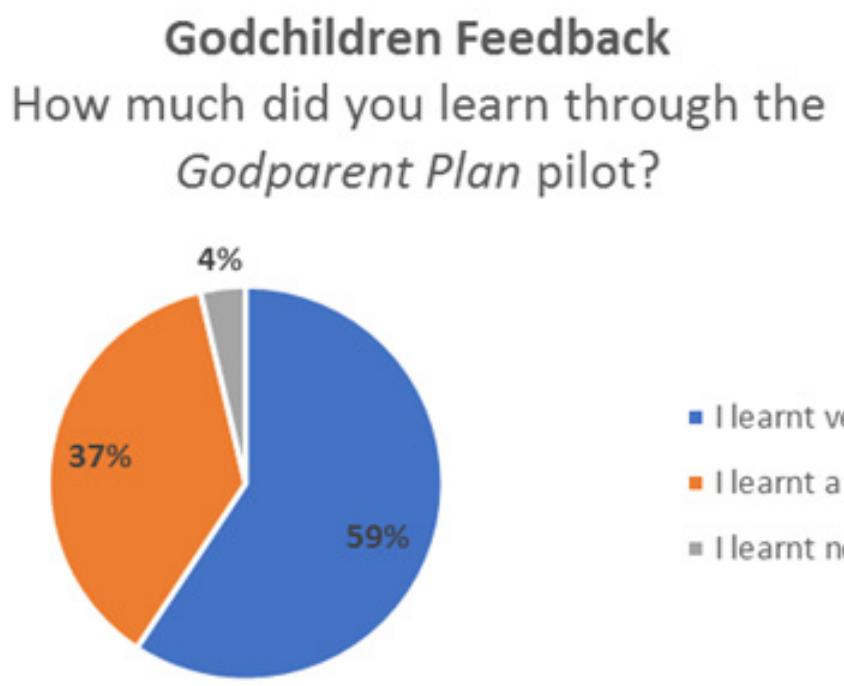

- Ilearnt very much

- I learnt a little

- I learnt nothing

Fig. 3. Godchildren' appreciation towards how much they learnt through the Godparent Plan pilot 
As can be seen from previous feedback, the majority in both groups claimed they had learnt through this didactical approach. However, as it is perceptible in Figure 4, the godparents were the ones who really took advantage of this process, gaining confidence towards their skills while teaching and mentoring their godchildren.

Supplementing the previous results, another question was asked to the participating students: Would you like to be part of a future Godparent Plan, as a godchild?

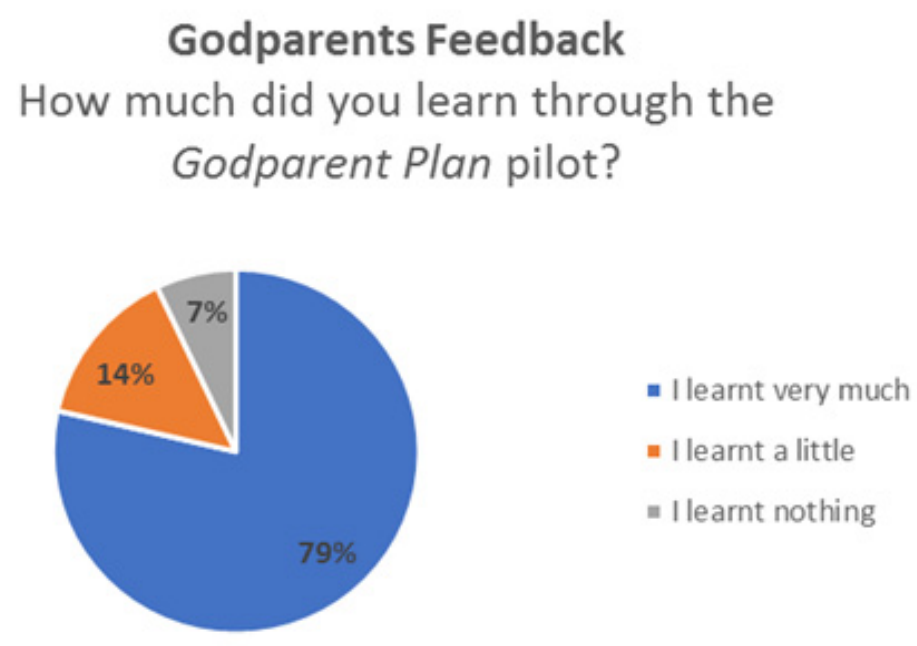

Fig. 4. Godparents' appreciation towards how much they learnt through the Godparent Plan pilot

\section{Godparents Feedback}

Would you like to be part of a future Godparent Plan, as a godchild?

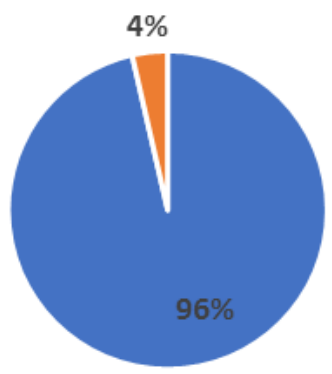

- Yes, I would like to

- No, I won't

Fig. 5. Godparents' interest towards being godchildren in a future Godparent Plan 
Visualizing Figure 5, a clear majority (96.4\%) of the godparents' population answered affirmatively to this previous question, with just $3.6 \%$ in disagreement with it. Similarly, as can be seen in Figure 6, the totality of godchildren answered affirmatively to the same question.

Taking another direction to complement results, another question was asked to the participant students: Would you like to be part of a future Godparent Plan, as a godparent?

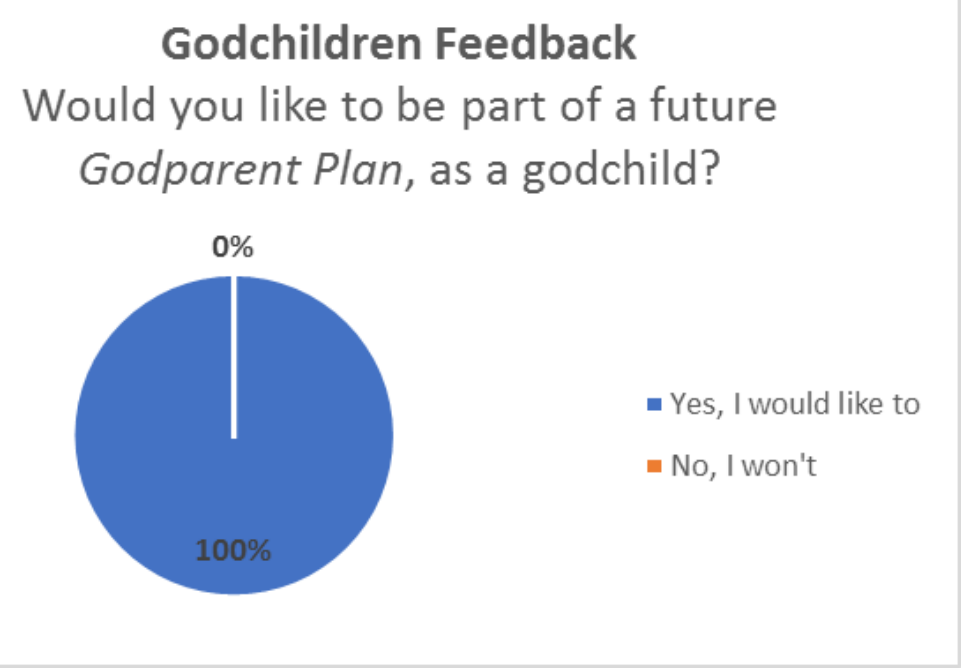

Fig. 6. Godchildren' interest towards being godchildren in a future Godparent Plan
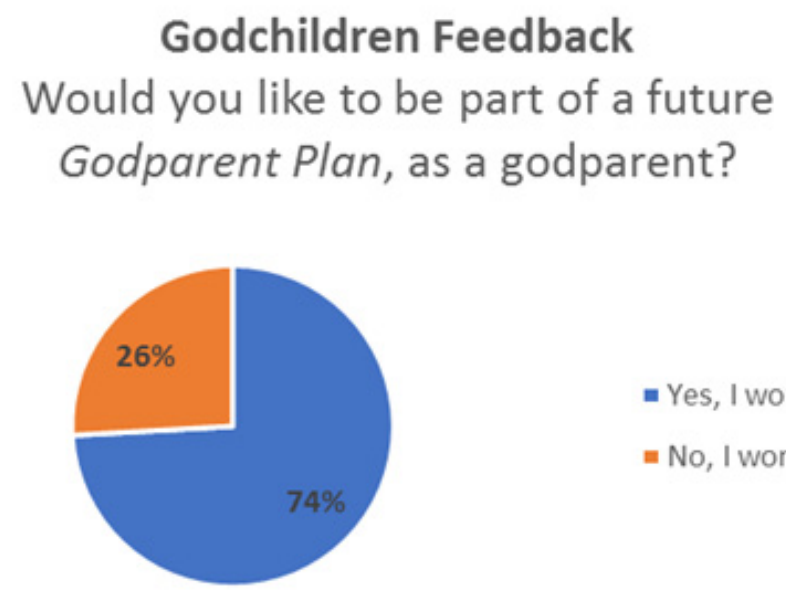

- Yes, I would like to

= No, I won't

Fig. 7. Godchildren' interest towards being godparents in a future Godparent Plan 
Considering what Figure 7 illustrates, $74 \%$ of the godchildren got motivated towards becoming godparents in a future Godparent Plan, which shows how successful was the plan when it comes to confidence gaining, motivation and career projection.

Similarly, as it is shown in Figure 8, a clear majority of $96 \%$ of the participant godparents answered affirmatively to the last question. This is evidence of the Godparent Plan's success, as an innovative didactical strategy well received by the students.

\section{Godparents Feedback \\ Would you like to be part of a future Godparent Plan, as a godparent?}

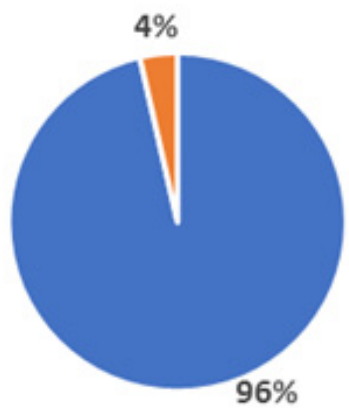

- Yes, I would like to

= No, I won't

Fig. 8. Godparents' interest towards being godparents in a future Godparent Plan

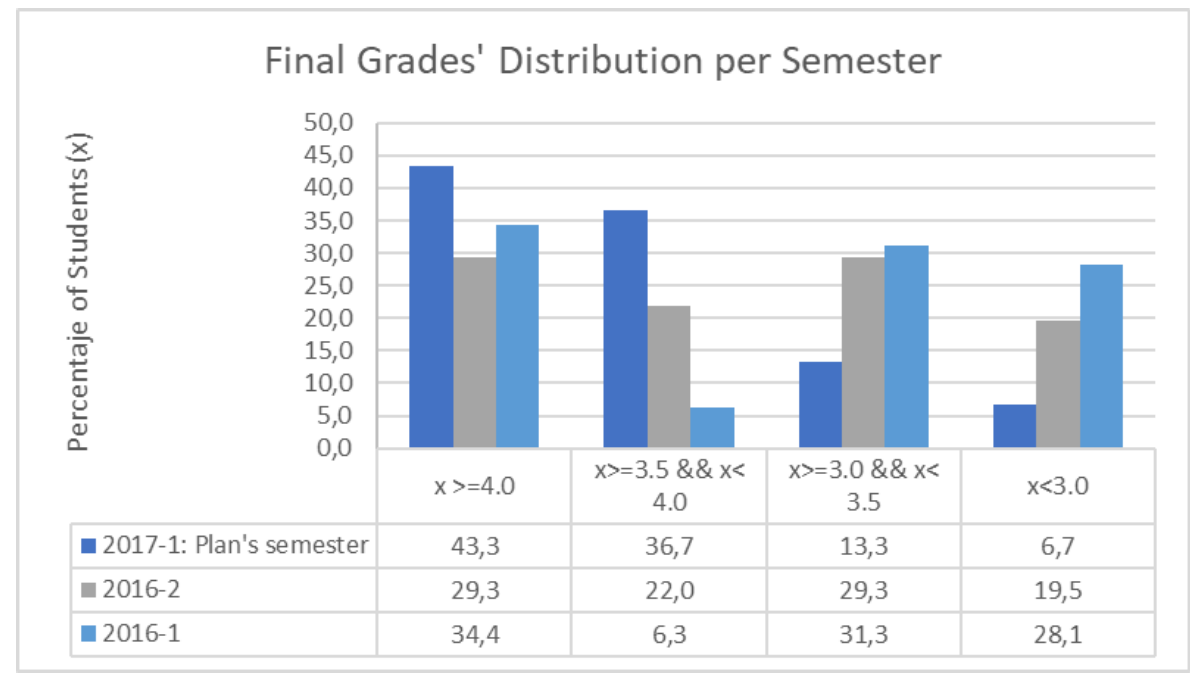

Fig. 9. Final Grades' Distribution per Semester 


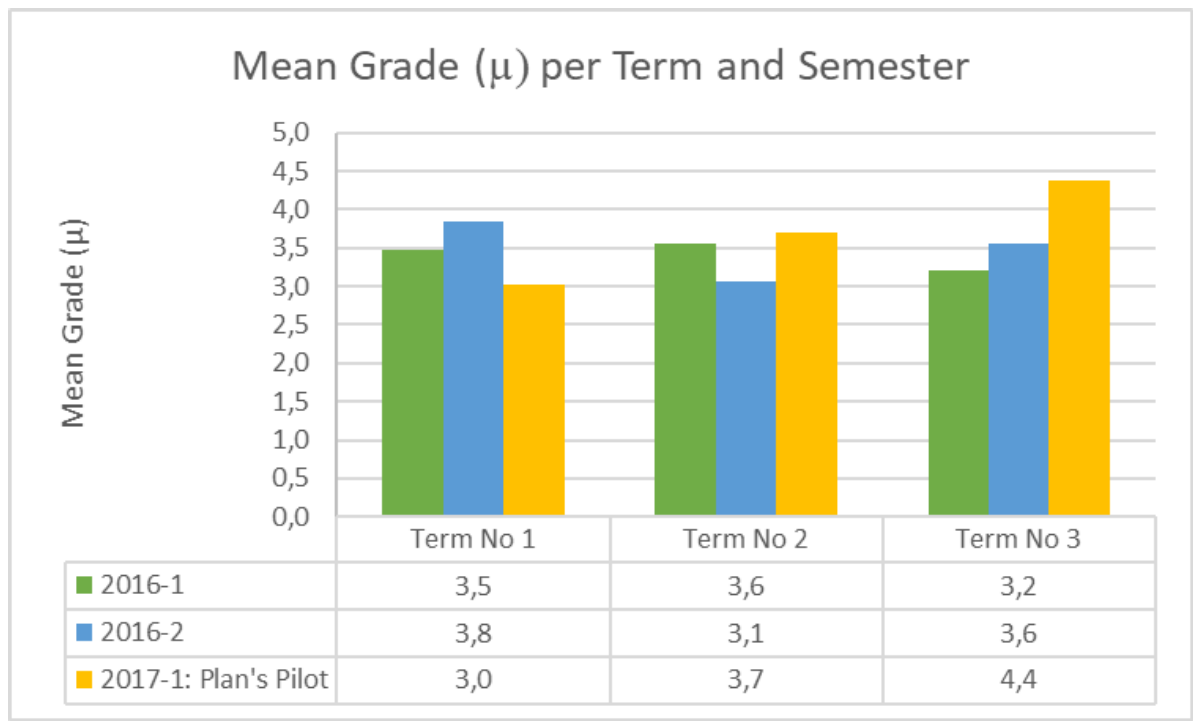

Fig. 10.Mean Grade $(\mu)$ per Term and Semester

Considering Figure 4 again, and the $78.6 \%$ who stated they had learnt very much, it is important to complement these results with the corresponding grades of CS2, having at the end of the pilot's semester (2017-1) just $6.7 \%$ of academic failure (See Figure 9), with more than the $40 \%$ of the population with a grade equal to or higher than 4.0 on a 5.0 scale. Furthermore, comparing the resulting grades with the two previous semesters for CS2, there was a significant improvement when it comes to final grades' distribution, considering that for the pilot's semester $80 \%$ of students reported a final grade equal to or higher than 3.5 in a 5.0 scale, in comparison with the $40.6 \%$ and $51.2 \%$ reported in the previous semesters: $2016-1$ and 2016-2.

Observing Figure 10, the application of this didactic approach increased the mean grade from the second to the third term, for the semester in which the Plan was applied. Moreover, the results according to the semester in which the plan was articulated, present higher grades specially for the final term.

Near $35 \%$ of the students' population in CS2, were academically successful with this strategy, evidencing significant learning after participating in this process. General godparents' opinions indicate that, because of the need for preparing the tutoring sessions, they had to study again and be prepared for topics asked by the godchildren. The experience of being asked and having no other choice than answering, conducted them to master topics covered in their first year at college, and to gain confidence while teaching and mentoring.

These results show how successful a tutoring approach, such as the Godparent Plan, can be towards deep and active learning. Setting up this pilot study involved the articulation of all of the dimensions proposed by Fink (see Chapter 3 ), and the feedback here provided by the students, in addition to the grades and statistics reported for this initiative, show how this type of didactics are of interest to them. 


\section{Conclusions}

Considering how the students received the didactical proposal, and how the results were obtained in both courses, especially in CS2, it can be concluded that the Godparent Plan is very effective for the godparents' (or tutors') academic enhancement, in terms of concepts and skills corresponding to programming. It was shown that the strategy was not just well received by both students' groups, but that it also presented excellent academic results in CS2 as a course.

Another conclusion is that peer tutoring is an excellent pedagogical strategy, which allows the student to go from understanding and memorizing concepts, to learn how to learn. The social interaction between tutors and tutees (godparents and godchildren), enhanced their communication, leadership and context understanding skills, in parallel to those skills required by a programming course, such as CS2.

Finally, it can be concluded that this first pilot was successful, considering that it was a very first approach in our program and in our institution. As it was shown before, the didactic strategy was effective in all directions, empowering students towards their educational process, and additionally, creating a collaborative atmosphere for learning and evolving as students.

\section{$7 \quad$ Future Work}

As future work, the Godparent Plan is to be conducted again, between CS1 and $\mathrm{CS} 2$, extending the execution time from four academic weeks to 16 academic weeks (one semester), seeking to generate various dynamics throughout the plan, with the rotation of godparents and godchildren, in conjunction with the approach of crosssectional activities between courses.

On the other hand, the Godfather Plan is to be considered not only for courses of the first academic year, but also for later courses. The implementation of this plan in later semesters, would allow to study how effective peer tutoring is for more advanced students, and how it can affect or motivate them towards their learning process.

Likewise, another approach would involve conducting a Godparent Plan between seniors and first-semester students, in order to compare pedagogical results between groups that have worked with godparents from different semesters. In this way, the effect of tutoring as a pedagogical mechanism in different semesters would be studied, characterizing its effectiveness with different approaches.

As it can be seen, this pilot study opens doors for further research, looking forward to study and understand peer tutoring success for students' academic improvement and retention. There are several pivots for this plan, which could be articulated and evaluated in other pedagogical contexts and scenarios, while improving it as a didactic strategy for significant learning. 


\section{Acknowledgment}

Our sincere gratitude goes to the students who actively participated in this first study. Their participation was essential for this study to succeed, since they efficiently collaborated and actively participated in all the proposed activities within the Godparent Plan.

\section{$9 \quad$ References}

[1] Cottam, J., Menzel, S., \& Greenblatt, J. (2011). Tutoring for retention. Paper presented at the 42nd ACM technical symposium on Computer science education (SIGCSE '11), pp. 213-218. https://doi.org/10.1145/1953163.1953227

[2] Loos, S., Menzel, S., and Poparad, M. (2005). Three perspectives on peer tutoring for CS1. In Proceedings of the Midwest Celebration of Women in Computing conference. Retrieved from: http://www.cs.indiana.edu/cgi-pub/midwic/papers/uploads/loos.pdf

[3] Weikle, D. A. (2015). A Peer Tutoring Model for Small Schools with Limited Funding and Resources (Abstract Only). Proceedings of the 46th ACM Technical Symposium on Computer Science Education - SIGCSE 15. https://doi.org/10.1145/2676723.2691886

[4] Hug, S., Thiry, H., \& Tedford, P. (2011). Learning to love computer science. Proceedings of the 42nd ACM technical symposium on Computer science education - SIGCSE 11. https://doi.org/10.1145/1953163.1953225

[5] Feijóo García, P., Medina Cortés, D., Ramírez Cajiao, M., \& Espinosa Díaz, E. (2017). Cooperative Learning Web Application for Water Care in Colombia - Manglar: ActorNetwork Theory Software Solution. International Journal Of Emerging Technologies In Learning (IJET), 12(04), pp. 208-216. https://doi.org/10.3991/ijet.v12i04.6733

[6] Feijoo Garcia, P., \& De la Rosa, F. (2016). RoBlock - Web App for Programming Learning. International Journal Of Emerging Technologies In Learning (IJET), 11(12), pp. 4553. https://doi.org/10.3991/ijet.v11i12.6004

[7] Fink, L. D. (2013). Creating significant learning experiences: an integrated approach to designing college courses. San Francisco: Jossey-Bass.

[8] Frager, S., \& Stern, C. (1970). Learning by Teaching. The Reading Teacher, 23(5), 403417. Retrieved from http://www.jstor.org/stable/20196333

[9] Cortese, C. G. (2005). Learning through Teaching. Management Learning, 36(1), 87-115. https://doi.org/10.1177/1350507605049905

[10] Villalobos, J. \& Casallas, R. (2006). Fundamentos de programación: aprendizaje activo basado en casos: un enfoque moderno usando Java, UML, objetos y eclipse (pp.187-196). Colombia: Pearson Education.

[11] Villalobos, J. (2008). Introducción a las estructuras de datos: aprendizaje activo basado en casos: un enfoque moderno usando Java, UML, objetos y eclipse (pp. 4 - 26). Colombia: Pearson Education.

\section{Authors}

Pedro Guillermo Feijóo García is a Core Faculty Assistant Professor of the Systems Engineering Program at Universidad El Bosque, Colombia, where he teaches core courses of the programming and algorithms line. Additionally, he is an active 
researcher of the research group OSIRIS\&BIOAXIS, particularly interested in the following research interests: Software engineering, social and human centered computing, instructional technologies, computer science education, robotics and computational biomechanics (e-mail: pfeijoo@unbosque.edu.co).

Carlos Hernán Ortíz Buitrago is a Core Faculty Assistant Professor of the Systems Engineering Program at Universidad El Bosque, Colombia, with more than 17 years of academic teaching experience in the programming and algorithms line. He is the current Program's Academic Coordinator. His research interests include: Software engineering, computer science education and education management (e-mail: carlosortiz@unbosque.edu.co).

Article submitted 16 August 2017. Resubmitted 19 November 2017. Final acceptance 04 February 2018. Final version published as submitted by the authors. 